\title{
Transparência de informações on-line disponibilizadas pelos institutos e universidades públicas do Rio Grande do Sul
}

\author{
Transparency of on-line information available by the institutes and \\ public universities of Rio Grande do Sul
}

\section{Transparencia de información en línea disponible por los institutos y universidades públicas de Rio Grande do Sul}

Matheus Fernandes Rotta ${ }^{1}$; Monize Sâmara Visentini ${ }^{1}$; Darlan Nei Writzl ${ }^{1}$

\section{RESUMO}

Os portais eletrônicos são mecanismos muito utilizados nas Instituições de Ensino Superior (IES), pois permitem o compartilhamento de dados e informações, não só à comunidade acadêmica como também, a toda a população. Considerados meios que possibilitam organizar informações de maneira adequada e objetiva, esses portais facilitam a administração e o gerenciamento institucional. Assim, este estudo teve como objetivo comparar o Índice de Divulgação das Universidades Federais (IndexDUF) obtido pelos Portais Eletrônicos dos Institutos e Universidades Públicas do Rio Grande do Sul. Para tanto, avaliaram-se os portais eletrônicos de onze instituições gaúchas, identificando a presença de informações relacionadas a cada uma das 11 categorias que compõem o IndexDUF. A categoria mais divulgada refere-se às Atividades acadêmicas (extensão), com média geral de divulgação de $90,91 \%$. A categoria mais divulgada por Institutos Federais (IFs) corresponde à Participação Eletrônica, e a mais divulgada pelas Universidades Federais (UFs) está relacionada às Atividades acadêmicas (extensão). Entre as menos divulgadas, estão às Características da Informação Financeira e Informação de Responsabilidade Social. A partir das análises dos resultados, conclui-se que a quantidade máxima de itens divulgados foi de 128, pela Universidade Federal da Fronteira Sul (UFFS), sendo que as instituições divulgaram, pelo menos, 97 dos 139 itens avaliados.

Palavras-chave: Transparência pública; Divulgação; Portais.

\begin{abstract}
Electronic portals are mechanisms widely used in Higher Education Institutions (HEI), as they allow the sharing of data and information to the entire population and not just the academic community. These portals are considered ways that make it possible to organize information properly, objectively and facilitate the administration and institutional management. Thus, this study had as objective to compare the Disclosure Index of Federal Universities (IndexDUF) obtained by the Electronic Portals of Public Institutes and Universities in Rio Grande do Sul. For this purpose, the electronic portals of eleven gaucho institutions were evaluated, identifying the presence of information related to each of the 11 categories that make up the IndexDUF. The most disclosed category refers to Academic activities (extension), with a general average of $90.91 \%$. The category most disclosed by Federal Institutes (IFs) corresponds to Electronic Participation, and the most disclosed by Federal Universities (UFs) is related to Academic Activities (extension). Among the least disclosed are the Characteristics of Financial Information and Social Responsibility Information. From the analysis of the results, it is concluded
\end{abstract}

\footnotetext{
${ }^{1}$ UFFS - Universidade Federal da Fronteira Sul, Cerro Largo/RS - Brasil.
} 
that the maximum number of items disclosed was 128, by the Federal University of Fronteira Sul (UFFS), is that the institutions disclosed at least 97 of the 139 items evaluated.

Keywords: Public transparency; Disclosure; Portals.

\section{RESUMEN}

Los portales electrónicos son mecanismos ampliamente utilizados en las Instituciones de Educación Superior (IES), ya que permiten compartir datos e información, no solo con la comunidad académica sino también con toda la población. Considerados medios que permiten organizar la información de manera apropiada y objetiva, estos portales facilitan la administración y la gestión institucional. Así, este estudio tuvo como objetivo comparar el Índice de Difusión de Universidades Federales (IndexDUF) obtenido por los Portales Electrónicos de Institutos y Universidades Públicas en Rio Grande do Sul. Para este propósito, se evaluaron los portales electrónicos de once instituciones gauchas identificando la presencia de informacines relacionadas con cada una de las 11 categorías que componen el IndexDUF. La categoría más publicitada se refiere a Actividades Académicas (extensión), con un promedio general de 90.91\%. La categoría más publicitada por los Institutos Federales (IF) corresponde a la Participación Electrónica, y la más publicitada por las Universidades Federales (UF) está relacionada con las Actividades Académicas (extensión). Entre las menos divulgadas se encuentran las Características de la información financiera y la Información de responsabilidad social. Del análisis de los resultados, se concluye que el número máximo de artículos divulgados fue 128, por la Universidad Federal de Fronteira Sul (UFFS), y las instituciones revelaron al menos 97 de los 139 artículos evaluados.

Palavras-chave: Transparencia pública; Divulgación; Portales.

\section{INTRODUÇÃO}

As instituições públicas de ensino superior dispõem de portais eletrônicos, os quais são considerados plataformas na web que possibilitam a troca de informações referentes à instituição, de maneira que esta seja transparente e sirva para que os stakeholders ${ }^{2}$ não só compreendam as atividades que são desenvolvidas pela mesma, como, também, tenham conhecimento sobre o gerenciamento e controle dos recursos públicos que estão sendo utilizados no desenvolvimento destas ações (ZORZAL, 2015).

Platt Neto, Cruz e Vieira (2006) ressaltam que as Universidades Federais e Estaduais são fundações dependentes de bens públicos, ou seja, necessitam de recursos governamentais para pôr em prática suas atividades institucionais. Por se tratarem de autarquias públicas, são consequentemente obrigadas pela Constituição Federal a reverenciar os princípios de gestão pública, transparecendo e prestando contas sobre como estes recursos estão sendo aplicados. Molina (2008) entende que a necessidade da implantação dos portais eletrônicos nas Instituições de Ensino Superior (IES) Federais vem justamente pelo fato de a sociedade contemporânea ser cada vez mais preocupada com o desenvolvimento das Tecnologias da Informação e Comunicação (TICs), que permitem que a comunidade estabeleça uma inter-relação com determinada instituição.

\footnotetext{
2 Stakeholders: atores (pessoa, grupo, entidade) que possuem algum tipo de relação ou interesses (diretos ou indiretos) com uma instituição (ZORZAL, 2015, p. 20).
} 
Trata-se no art. 8. ${ }^{\circ}, \S 2 .{ }^{\circ}$, da Lei 12.527/2011 (BRASIL, 2011), Lei de Acesso à Informação (LAI), que os órgãos e entidades públicas devem utilizar a rede de internet para demonstrar como são geridos os recursos públicos na instituição. Além dos portais eletrônicos, devem fazer o uso de todos os mecanismos que tiverem disponíveis para divulgar suas ações. Complementarmente, o § 3.0 impõe que estes portais devem conter ferramenta de pesquisa de conteúdo que permitam o acesso à informação de forma objetiva, transparente, clara e em linguagem de fácil compreensão (BRASIL, 2011).

A grande maioria dos portais das Universidades Públicas Federais, de acordo com Rodrigues (2013), apresenta poucos esclarecimentos em relação aos aspectos exigidos pela LAI. Monteiro (2014), Pessôa et al. (2018) e Melo (2019) corroboram tal assertiva, indicado que essas instituições ainda precisam evoluir no que se refere à efetivação da LAI. Por se tratar de um ambiente onde são produzidos conhecimentos, Rodrigues (2013) alega que a cultura de acesso à informação deve ser frequentemente discutida, já que permite que os indivíduos levantem distintos julgamentos e opiniões em relação ao uso dos recursos públicos.

No Rio Grande do Sul, as Universidades Federais (UFs) (UFSM, UFFS, UNIPAMPA, UFPEL, UFRGS, UFCSPA, FURG), os Institutos Federais (IFs) (IFFar, IFRS, IFSul) e a Universidade Estadual do Rio Grande do Sul (UERGS) dispõem de portais eletrônicos, os quais são estudados nesta pesquisa, com o intuito de identificar qual o índice de transparência das informações neles fornecidas.

A presente pesquisa é realizada através do Índice de Divulgação das Universidades Federais (IndexDUF), uma métrica elaborada por Pessôa (2013), para determinar a transparência presente dos portais de instituições de ensino. Pessôa (2013) afirma que o IndexDUF ser utilizado tanto para Universidades, quanto para Institutos Federais, afinal, trata-se de um índice que mantém itens estabelecidos pela legislação brasileira. O IndexDUF aborda questões referentes aos dados gerais da instituição, às atividades acadêmicas de ensino, pesquisa e extensão, informação financeira e de gestão, características da informação financeira, informação sobre responsabilidade social, informação sobre condições de qualidade administrativa e acadêmica da instituição, informação relativa à navegabilidade, acesso e desenho da página web, informação eletrônica (E-Informação), serviços eletrônicos (E-Serviços), participação eletrônica (E-Participação) e itens correspondentes a LAI.

Com intuito de trazer maiores esclarecimentos sobre a gestão pública e a transparência nos portais das instituições Federais e Estaduais do Rio Grande do Sul, o trabalho em questão visa responder ao seguinte questionamento: "Qual o índice IndexDUF de transparência das informações fornecidas pelos Portais Eletrônicos dos Institutos e Universidades Públicas do Rio Grande do Sul?".

Este estudo teve como objetivo comparar o índice IndexDUF de transparência das informações fornecidas pelos Portais Eletrônicos dos Institutos e Universidades Públicas do Rio Grande do Sul. O estudo é relevante para a sociedade, pois permite uma melhor compreensão das atividades acadêmicas de ensino, pesquisa e extensão que estão, ou não, sendo desempenhadas pelas instituições. A partir do momento em que a sociedade passa a receber informações sobre como estão sendo destinados os recursos públicos dentro das Universidades, a mesma tende a desenvolver maior confiança sobre a instituição, percebendo que autarquia de ensino atua de forma racional, não restringindo suas informações aos stakeholders (ZÉMOR, 2009). 
Em relação à utilidade prática, acredita-se que esta pesquisa poderá demonstrar aos stakeholders, gestores, governo, e demais partes interessadas, como essas IES divulgam virtualmente suas informações de gestão. Também se espera que o estudo contribua para que os gestores dos Institutos e Universidades estudados identifiquem, nos portais eletrônicos das respectivas instituições, as possíveis ausências de informações, permitindo assim, que estas possam, futuramente, ser implantadas (ZORZAL, 2015).

\section{A TRANSPARÊNCIA DAS INFORMAÇÕES E O INDEXDUF}

As instituições públicas de ensino passaram a transparecer seus processos no intuito de estimular a participação dos cidadãos e informá-los sobre o seu gerenciamento. Para Rodrigues (2013), os portais das IES Federais e Estaduais devem se enquadrar nas mesmas exigências dos portais do estado, interagindo e comunicando de forma a buscar maior compreensibilidade e acessibilidade às informações, além de disponibilizá-las de forma clara e objetiva.

Agostineto e Raupp (2010) expressam que o processo de implantação dos portais eletrônicos nas IES possibilitou que o cidadão tivesse acesso mais próximo às suas atividades e serviços, elevando seu grau de acessibilidade e cultura social, além de trazer estímulos às exigências relacionadas a democracia e a prestação de contas da instituição. A iniciativa dos órgãos públicos "de dar divulgação e informações de interesse geral ou coletivo, ainda que não tenha sido expressamente solicitada, é denominada de princípio da Transparência Ativa" (CONTROLADORIA GERAL DA UNIÃO, CGU, 2013, p. 14). Sobre esse princípio, é descrito na LAI, no seu art. $7^{\circ}$ que "é dever dos órgãos e entidades promover, independente de requerimento, a divulgação em seus sítios na Internet de informações de interesse coletivo ou geral por eles produzidas ou custodiadas". Assim, que as instituições públicas de ensino devem cumprir com essa exigência, disponibilizando informações, de fácil entendimento e acesso.

No intuito de compreender os índices de transparência ativa que foram determinados a partir da análise dos portais eletrônicos IES, Pessôa (2013) desenvolveu o IndexDUF. Para que essa métrica fosse considerada eficiente e eficaz, o autor baseou-se nos índices desenvolvidos por Dixon, Coy e Tower (1993), Rosario, Pérez e Cañadas (2011) e Católico (2011).

A métrica IndexDUF é constituída por 11 categorias: Categoria 1 - Dados gerais da instituição, Categoria 2 - Atividades acadêmicas de ensino, Categoria 3 - Atividades acadêmicas de pesquisa, Categoria 4 - Atividades acadêmicas de extensão, Categoria 5 - Informação financeira e de gestão, Categoria 6 - Características da informação financeira, Categoria 7 - Informação sobre responsabilidade social, Categoria 8 - Informação sobre condições de qualidade administrativa e acadêmica da instituição, Categoria 9 - Informação relativa a navegabilidade, desenho e acessibilidade, Categoria 10 - E-Serviços e Categoria 11 - E-Participação.

Tratando-se especificamente dessas categorias, cabe uma breve discussão a respeito de cada uma delas. De acordo com Lima et al. (2017), às atividades acadêmicas de ensino, pesquisa e extensão (Categorias 2, 3 e 4) possibilitam que os acadêmicos estabeleçam relações mais amplas às distintas formas de conhecimento, fazendo com que os mesmos encontrem diversas alternativas que possam expandir seu campo de visão e facilitar o processo de tomada de decisões. Essa exposição do acadêmico às práticas profissionais permite que desenvolva distintas habilidades no gerenciamento de dados e informações, de forma a enfrentar de maneira mais eficiente as possíveis situações- 
problema que encontrar. Lima et al. (2017) incrementam que atividades de ensino, pesquisa e extensão são grandes responsáveis pela formação acadêmica diferenciada dos indivíduos, possibilitando que os mesmos tenham diferentes percepções sobre as ações desenvolvidas pela sociedade em que permeiam.

Além de manter a indissociabilidade sobre as atividades de ensino pesquisa e extensão, a instituição deve estabelecer de forma clara e direta as informações financeiras (Categoria 5) e de gestão para que os indivíduos possam, assim, ter maior compreensibilidade do gerenciamento financeiro da mesma. Faria (2012) entende que, para uma instituição poder apresentar suas informações financeiras e gerenciais à comunidade, a mesma deve dispor de instrumentos de comunicação ou documentos como: balanços, demonstrações de resultado do exercício (DRE), indicadores ambientais, relatórios de gestão, redes sociais, atas, boletins informativos, correio eletrônico, página na web, dentre outros.

A responsabilidade social (Categoria 7) e as condições de qualidade administrativa e acadêmica da instituição (Categoria 8) são questões que refletem de forma abundante no seu desenvolvimento. Isso porque, as ações de proteção ambiental, que estão ligadas à responsabilidade de economia e preservação dos recursos naturais, estão cada vez mais presentes nas instituições, conscientizando estas autarquias a diminuir a utilização de insumos que gerem desgastes ao ambiente (KON, 2013). A responsabilidade social das instituições parte da ideia de que as IES são as grandes responsáveis pelas ações que modificam a sociedade, justo que, estas devem tomar cuidados ao exercer determinadas ações, pois estas podem afetar diretamente a sociedade tanto de forma positiva, quanto negativa (TOMEI, 1984).

Tomei (1984) complementa que os aspectos da responsabilidade social podem interferir na qualidade administrativa e acadêmica da instituição, pois a mesma envolve interesses sociais que, de certa forma, afetam a qualidade de vida da população. Davok (2007) também compreende que as condições de qualidade administrativa e acadêmica da instituição podem ser interpretadas de várias formas, tanto pelo fato de a qualidade de educação possibilitar que o acadêmico domine os conteúdos propostos pelas disciplinas, quanto pelo desenvolvimento das capacidades técnicas e das visões críticas sobre determinados fatores.

Oliveira, Fonseca e Amaral (2006) expressam que a qualidade da gestão e da educação acadêmica está ligada à relevância que a instituição dá aos seus processos avaliativos. A avaliação se transforma no elemento que mede a qualidade em que o ensino e pesquisa estão sendo aplicados, interferindo também em questões de gerenciamento e extensão, que estão intrinsecamente ligadas às regulamentações e critérios do sistema educacional.

Rosario, Pérez e Cañadas (2011) ressaltam que a disponibilização de informações on-line facilita o processo de transparência nas instituições e, consequentemente, permite que haja maiores interações e questionamentos sobre as questões financeiras ou não. Para isso, torna-se fundamental que as instituições tenham presentes em seus portais eletrônicos aspectos referentes à Serviços Eletrônicos (E-Serviços), Participação Eletrônica (E-Participação), Navegabilidade, Desenho e Acessibilidade (Categorias 9, 10 e 11).

Indolfo (2014) reforça que a presença de informações deve ser cada vez mais sólida nas instituições, isso porque, elas possibilitam o desenvolvimento de avanços sociais, econômicos e políticos. Além 
disso, quando as IES disponibilizam informações nos seus portais virtuais, elas facilitam o processo de entendimento dos stakeholders sobre as funções e conteúdos que os agentes públicos desempenham dentro das instituições (FARACO, 2015).

\section{PERCURSO METOdOLÓgICO}

O presente estudo, voltado à análise da transparência de informações nos portais eletrônicos das IES Públicas do Rio Grande do Sul, foi desenvolvido de forma quantitativa. Este procedimento metodológico, de acordo com Richardson (1999), é aplicado comumente em estudos descritivos que buscam encontrar informações que serão utilizadas na caracterização dos resultados obtidos na pesquisa. O corte da investigação foi transversal único, que se refere, segundo Malhotra (2012), ao estudo no qual as informações são obtidas uma única vez.

Para tanto, realizou-se um censo, identificando, através do índice IndexDUF, a transparência das informações fornecidas pelos Portais Eletrônicos dos Institutos e Universidades Federais e Estaduais do Rio Grande do Sul uma única vez. Diferentemente da pesquisa amostral, o censo realiza análises sobre o todo e não somente à uma determinada amostra. Os resultados obtidos através do censo auxiliam na tomada de decisões sobre investimentos e criações de novas políticas públicas. Serão analisados os portais de toda a população de Universidades e Institutos Públicos do Rio Grande do Sul (INSTITUTO BRASILEIRO DE GEOGRAFIA E ESTATÍSTICA, IBGE, 2020).

De acordo com o Atlas Socioeconômico do Rio Grande do Sul (2017), o estado há uma ampla rede de ensino superior, com instituições de destaque em vários municípios, sendo que no ano de 2017 contava com 21 Universidades, 7 Centros Universitários, 103 Faculdades e 3 Institutos Federais de Educação Ciência e Tecnologia. A partir dessas informações, as 11 IES Públicas do Rio Grande do Sul analisadas foram: Universidade Federal de Santa Maria (UFSM), Universidade Federal da Fronteira Sul (UFFS), Universidade Federal do Pampa (UNIPAMPA), Universidade Federal de Pelotas (UFPEL), Universidade Federal do Rio Grande do Sul (UFRGS), Universidade Federal de Ciências da Saúde de Porto Alegre (UFCSPA), Universidade Federal do Rio Grande (FURG), Instituto Federal Farroupilha (IFFar), Instituto Federal do Rio Grande do Sul (IFRS), Instituto Federal Sul-rio-grandense (IFSul) e uma estadual compreendida pela Universidade Estadual do Rio Grande do Sul (UERGS).

Os dados foram coletados através da realização de visitas nos portais de cada instituição estudada, seguindo o protocolo de 6 passos indicado por Pessôa (2013): 1) visitar o portal da instituição; 2) utilizar a ferramenta de busca do Google; 3) buscar cada item indicando com (1) a sua ocorrência e com (0) a sua ausência; 4) utilizar a ferramenta de busca do próprio portal da instituição; 5) buscar através do mapa do site e; 6 ) revisar os registros. A tabulação dos dados foi realizada através do LibreOffice, utilizando-se o LibreOffice Calc.

Na Tabela 1 destacam-se as categorias do IndexDUF e o número de itens avaliados em cada uma delas (PESSÔA, 2013).

Os itens que compõem cada uma das categorias foram identificados através de um processo binário, em que 0 indica que este elemento não está presente no portal de determinada instituição, e 1 indica a presença deste item no portal eletrônico (PESSÔA, 2013). Todos os elementos compostos no IndexDUF apresentam o mesmo peso, ou seja, no processo de medição dos dados o índice apresenta 
ausência de ponderabilidade. Após a coleta dos dados, elaborou-se um índice percentual, informando o quão transparente é cada uma das instituições.

Tabela 1 - Componentes do IndexDuf

\begin{tabular}{clc}
\hline Ordem & \multicolumn{1}{c}{ Categorias } & $\begin{array}{c}\text { Número de } \\
\text { itens* }\end{array}$ \\
\hline $\mathbf{1}$ & Dados Gerais da Instituição & 24 \\
$\mathbf{2}$ & Atividades acadêmicas (ensino) & 12 \\
$\mathbf{3}$ & Atividades acadêmicas (pesquisa) & 9 \\
$\mathbf{4}$ & Atividades acadêmicas (extensão) & 3 \\
$\mathbf{5}$ & Informação financeira e de gestão & 40 \\
$\mathbf{6}$ & Características da informação financeira & 6 \\
$\mathbf{7}$ & Informação sobre responsabilidade social & 3 \\
$\mathbf{8}$ & Informação sobre condições de qualidade administrativa e & 5 \\
$\mathbf{9}$ & acadêmica da instituição & Informação relativa à navegabilidade, acesso e desenho da \\
$\mathbf{1 0}$ & Eágina web & 20 \\
$\mathbf{1 1}$ & E-perviços & 8 \\
\hline & & 9 \\
\hline
\end{tabular}

*O detalhamento dos itens que compõe a categoria pode ser encontrado em Pêssoa (2013) com a respectiva numeração referenciada neste trabalho.

Fonte: Elaborada pelos autores, 2020.

Os resultados encontrados foram identificados a partir da avaliação do índice de transparência de cada categoria que compõe o IndexDUF, utilizando-se a estatística descritiva para a análise, por meio da frequência dos casos observados. Após, fez-se uma apresentação geral, indicando o IndexDUF final de cada instituição.

\section{RESULTADOS E DISCUSSÕES}

\subsection{Identificação e comparação do IndexDUF das IES estudadas}

Inicialmente identificou-se o percentual de transparência dos portais institucionais de cada categoria do IndexDUF. Na sequência, realizou-se a análise individual para os IFs e as UFs, analisando àquelas com maior e menor percentual de divulgação. Pôde-se verificar também a ausência na publicação de determinados itens.

Durante o processo de coleta de dados foram descobertos alguns aspectos relevantes que auxiliaram na construção do detalhamento das informações obtidas sobre cada instituição. A Tabela 2 revela o nível médio de divulgação geral e o nível médio de cada categoria, considerando-se o grupo dos Institutos Federais e das Universidades. 
Tabela 2 - Categorias do Índice de Divulgação da População Investigada

\begin{tabular}{|c|c|c|c|c|}
\hline Ord. & Categorias & $\begin{array}{l}\text { Percentual de } \\
\text { divulgação } \\
\text { Institutos } \\
\text { Federais }\end{array}$ & $\begin{array}{l}\text { Percentual de } \\
\text { divulgação } \\
\text { Universidades }\end{array}$ & $\begin{array}{l}\text { Percentual médio } \\
\text { de divulgação da } \\
\text { categoria }\end{array}$ \\
\hline 1 & Dados gerais da instituição & $84,72 \%$ & $84,90 \%$ & $84,85 \%$ \\
\hline 2 & Atividades acadêmicas (ensino) & $58,33 \%$ & $81,25 \%$ & $75,00 \%$ \\
\hline 3 & Atividades acadêmicas (pesquisa) & $88,89 \%$ & $88,89 \%$ & $88,89 \%$ \\
\hline 4 & Atividades acadêmicas (extensão) & $88,89 \%$ & $91,67 \%$ & $90,91 \%$ \\
\hline 5 & Informação financeira e de gestão & $86,67 \%$ & $86,88 \%$ & $86,82 \%$ \\
\hline 6 & $\begin{array}{l}\text { Características da informação } \\
\text { financeira }\end{array}$ & $55,56 \%$ & $70,83 \%$ & $66,67 \%$ \\
\hline 7 & $\begin{array}{l}\text { Informação sobre responsabilidade } \\
\text { social }\end{array}$ & $44,44 \%$ & $70,83 \%$ & $63,64 \%$ \\
\hline 8 & $\begin{array}{l}\text { Informação sobre condições de } \\
\text { qualidade administrativa e } \\
\text { acadêmica da instituição }\end{array}$ & $73,33 \%$ & $80,00 \%$ & $78,18 \%$ \\
\hline 9 & $\begin{array}{l}\text { Informação relativa à } \\
\text { navegabilidade, acesso e desenho } \\
\text { da página web }\end{array}$ & $75,00 \%$ & $76,88 \%$ & $76,36 \%$ \\
\hline 10 & E-Serviços & $87,50 \%$ & $9063 \%$ & $89,77 \%$ \\
\hline 11 & E-Participação & $92,59 \%$ & $86,11 \%$ & $87,88 \%$ \\
\hline & Média de divulgação geral & $75,99 \%$ & $82,62 \%$ & $80,81 \%$ \\
\hline
\end{tabular}

Fonte: Elaborada pelos autores, 2020.

Mediante os dados da Tabela 2, a análise das categorias apresenta média de divulgação geral de $80,81 \%$ entre todas as Universidades e Institutos Federais presentes no estudo. Dentre as categorias, destaca-se como a mais divulgada as Atividades acadêmicas de extensão, possuindo um nível de divulgação de 90,91\%, seguida pela categoria E-serviços, a qual apresenta uma divulgação 89,77\%. Já a categoria relacionada à Informação sobre Responsabilidade Social é menos divulgada, com nível de divulgação de 63,64\%, seguida da categoria relacionada às Características da Informação Financeira, com divulgação de 66,67\%.

Dentre as 11 IES estudadas, encontram-se 3 institutos (IFRS, IFFar e IFSul) que apresentam média de divulgação geral de 75,99\%. Além disso, as 9 universidades (UERGS, UFFS, UFCSPA, UFPEL, UFSM, UNIPAMPA, FURG e UFRGS) apontam $82,62 \%$ na sua média geral de divulgação, ou seja, maior que a média dos IFs.

Dentre as categorias, a mais divulgada pelos IFs em comparação às UFs (incluindo a UERGS) é a categoria 11 E-Participação (Participação Eletrônica), com percentual de 92,59\%, enquanto as UFs manifestam $86,11 \%$. Todas as demais categorias apresentam índice de divulgação maior nas UFs do que nos IFs. Pessôa (2013) expressa que é relevante efetuar tal análise das categorias exibidas, 
permitindo o destaque das principais dificuldades nos portais das Universidades e Institutos Federais, assim como os seus pontos positivos em relação à divulgação.

A categoria 1 diz respeito aos Dados gerais da instituição. Sua estrutura é composta por 24 itens dos quais caracterizam, conforme Pessoa (2013), não só aspectos ligados à regulamentação da instituição, como também à sua estrutura administrativa. Essa categoria apresenta uma média geral de $84,85 \%$ sobre 24 itens pesquisados, sendo que 15 deles alcançaram um índice percentual de $100 \%$ de divulgação. Apesar do item 7 (Relação nominal e breve resumo dos diretores) ter sido considerado $100 \%$ divulgado, UERGS, UFFS, UFCSPA apresentam apenas a relação nominal dos seus reitores e vice reitores não sendo encontrados os demais diretores. Na UFSM, UNIPAMPA, FURG e UFRGS é encontrada a relação nominal dos diretores, porém não os resumos sobre suas trajetórias profissionais.

Em se tratando das informações menos divulgadas, está o rol das que tenham sido classificadas e desclassificadas por grau de sigilo nos últimos 12 meses (item 24), com um percentual de divulgação correspondente a $27,27 \%$, seguida por questões ligadas às especificações de salários (45,45\%) (item 23), forma de chegar à instituição $(54,55 \%)$ (item 21 ) e quantidade de pedidos de informação recebidos, atendidos e indeferidos (54,55\%) (item 22 ). Sobre o item 22, foram localizados pedidos recebidos apenas no ano de 2017 no IFFar e na FURG.

Contudo, sobre os itens que se encontram entre $100 \%$ e $60 \%$ estão à agenda do reitor (item 16), lista de contatos de funcionários (item 17), dados bibliográficos do reitor e vice-reitores (item 18), órgãos de gestão e funções (item 19) e funcionários por faculdade (item 20). A agenda do reitor foi encontrada em 9 das 11 instituições. Entretanto, a UERGS apresenta agenda, mas não especifica que é do reitor; e a UFPEL apresenta agenda, porém a mesma se encontra vazia.

No que concerne aos aspectos obrigatórios pela LAI, os itens 13 e 14 correspondentes aos telefones e endereços das unidades e setores da entidade, apresentam um índice de $100 \%$ de divulgação. Em contrapartida, com 27,27\% de divulgação, está o item 24, considerado o item menos divulgado da categoria. O item 12, informações sobre salários, é identificado em 5 das 11 instituições, porém esses dados são encontrados somente até 2017 no IFRS e na FURG; e no IFSul são encontradas "Tabelas salariais". Em relação à categoria 1, a média de divulgação encontrada nos IFs é de $84,72 \%$, enquanto nas UFs é de $84,90 \%$, ou seja, praticamente inexiste variação percentual entre os grupos analisados.

Assim, a categoria 1 (Dados gerais da instituição) acompanha diversos processos que ocorrem nas Universidades/Institutos e apresenta resultado suficiente de transparência na maioria dos itens analisados. Além disso, no que tange as distintas formas de conhecimento, que constituem e colaboram para o desenvolvimento dos alunos, estão as atividades acadêmicas de ensino, das quais permitem a execução das ofertas de programas de graduação, acesso à editais para contratação de professores, emprego e destino de estudantes entre outros, discutidos na sequência.

A categoria 2, Atividades acadêmicas (ensino), é formada por 12 itens, que competem a aspectos ligados à composição discente e docente da instituição. Também se refere à oferta de cursos, contratações, programas etc. Esta categoria apresenta uma média menor que a anterior, alcançando apenas $75 \%$ de divulgação nos portais eletrônicos das instituições.

Dos 12 itens encontrados nessa categoria, apenas 6 apresentam um índice de divulgação acima dos $80 \%$, com maior destaque aos aspectos ligados ao acesso de ferramentas tecnológicas e eletrônicas 
(item 4) ${ }^{3}$, editais públicos para a contratação docente (item 3), a relação nominal ou numérica da composição docente (item 2) e a oferta de programas de graduação e pós-graduação (item 1), os quais são divulgados por todas as Universidades e Institutos pesquisados. 0 item 5, o qual busca identificar se a instituição pública a relação nominal de programas para a formação de docentes, foi encontrado em 10 das 11 instituições. No IFFar e no IFSul foi encontrada a composição docente, porém não em lista. Este item não foi identificado apenas no IFRS.

As informações que correspondem ao destino dos estudantes egressos (item 10) e o detalhamento da distribuição do corpo discente por cursos, centros e faculdades (item 11) encontram-se abaixo dos $50 \%$ de divulgação, sendo que o ponto mais crítico encontrado na categoria é a lista dos alunos formados (item 12), com 18,18\%, localizada somente em duas instituições de ensino superior (UERGS e UFRGS). O item 10, emprego/destino dos estudantes da educação, foi identificado em 5 instituições, sendo que o IFSul divulga uma empresa formada por alunos e ex-alunos que investe em tecnologia para alavancar negócios. Na UERGS são divulgadas informações sobre alunos que foram selecionados e estão realizando mestrados. Na UFFS e FURG são divulgadas informações sobre o destino de alguns alunos, porém não de todos. Na UNIPAMPA o direcionamento do portal leva à janela "em construção".

No item 7, enunciação do número de estudantes matriculados em graduação e pós-graduação (índice de $72,73 \%$ ), foram encontrados dados de 2009 no IFRS. Já na UFFS e na UFPEL obtiveram-se dados referentes ao ano de 2017 e nas instituições como UERGS, FURG e UFRGS ao ano de 2018. Outro item com o mesmo percentual de divulgação é o referente à descrição da qualificação dos docentes (item 8), onde o IFSul apresentou uma extensão para o currículo Lattes dos docentes. Na UFPEL, as informações não foram encontradas na sua totalidade, apenas em alguns cursos. Na UFRGS, os dados foram encontrados, mas não todos, afinal a aba do portal informava que os docentes eram doutores e mestres, entretanto, não especificaram em quê.

Sobre a categoria 2, os IFs indicaram um percentual geral de 58,33\%, um índice discrepante se comparado ao percentual apresentado nas UFs (81,25\%). Isso se deve ao fato de que em nenhum dos 12 itens que compõem a categoria 2, os IFs apresentaram percentual de divulgação maior que as UFs, somente equivalências percentuais nos itens 1 a 4. Nenhum dos Institutos disponibilizou lista de alunos formados (item 12) e apenas duas Universidades, UERGS e UFRGS, a apresentaram em seus portais. Em relação ao destino dos estudantes (item 10), apenas um IF apresentou este item além de $50 \%$ das 8 Universidades. Apenas um Instituto Federal (IFSul) divulga o percentual de estudantes na faculdade, detalhando a distribuição do corpo discente por cursos, centros e faculdades. Além disso, 4 das 8 universidades apresentam o item 11 (percentual de estudantes na faculdade) em seus portais eletrônicos (UFFS, UFCSPA, FURG e UFRGS).

Já a categoria 3, referente às Atividades acadêmicas de pesquisa, apresenta itens com percentuais mais elevados, sendo que o menor índice possui é de 72,73\%. Composta por 9 itens, esta categoria é estruturada com informações pertinentes aos grupos, projetos, linhas e redes de pesquisa, assim como, apresenta aspectos referentes à trabalhos desenvolvidos por alunos ou assistentes de pesquisa. Dentre todas as categorias que compõem o IndexDUF, pode-se dizer que esta apresentou grande representatividade sobre as demais, já que foi a $3^{a}$ mais divulgada, com uma média percentual de $88,89 \%$, dentre as 11 categorias analisadas.

\footnotetext{
${ }^{3}$ Os itens são numerados para cada categoria.
} 
O maior destaque da categoria está nos itens 1 a 5, correspondentes ao: Registro de alunos em pesquisa ou assistentes de pesquisa (item 1), enunciação de linhas de pesquisa institucionais ou dos grupos de pesquisa (item 2), enunciação dos grupos de pesquisa (item 3), enunciação dos projetos de pesquisa (item 4) e relação das revistas ou de documentos que utilizam para divulgar os resultados dos processos de pesquisa formal (item 5), todos $100 \%$ divulgados pelas 11 instituições estudadas.

A média de divulgação geral dos IFs e UFs é equivalente nesta categoria. Porém, os IFs ultrapassam o nível de divulgação das UFs nos itens 6 e 8 , relacionados às patentes e segredos nacionais/internacionais e na relação das redes de pesquisa nas quais participam alunos ou assistentes de pesquisa, respectivamente.

Também é relevante a categoria 4, correspondente às Atividades acadêmicas (extensão), com o maior índice de divulgação entre as 11 categorias. Composta por somente três itens, apresentou uma média de divulgação de 90,91\%, sendo que 2 dos 3 itens apresentam 100\% de divulgação em todas as instituições pesquisadas. Todas as IES apresentam informações ligadas a programas ou atividades de difusão do conhecimento como cursos, formados, seminários e/ou oficinas (item 1) e divulgam as atividades de serviço tendentes a procurar o bem estar da comunidade (item 2).

Oito das onze instituições apresentam a enunciação de atividades ligadas à consultoria (item 3), tais como, empresas juniores que são formadas dentro das instituições de ensino com intuito de ofertar experiências práticas aos acadêmicos, preparando-os para o mercado de trabalho. Entretanto, o item 3 gerou um percentual de $72,73 \%$, o mais baixo da categoria.

Como já ressaltado, o IndexDUF compõe alguns itens exigidos pela LAI. Em relação a estes aspectos, a categoria 4 compõe dois destes itens (enunciação de programas e/ou atividades de difusão do conhecimento, e, enunciação de atividades de serviço tendentes a procurar o bem-estar da comunidade), que são amplamente divulgados ou estão presentes em todas as instituições estudadas. O percentual de transparência dos 3 IFs nesta categoria encontra-se em 88,89\%, ficando menor que o percentual geral das 8 universidades (91,67\%), pois o item 3 é encontrado em 2 dos 3 institutos e em 6 das 8 universidades. A categoria 4 apresentou uma média alta (90,91\%) em relação as demais, talvez pelo fato de ser uma categoria com poucos itens.

A categoria 5 é a com a maior quantidade de itens, sendo 40 itens na totalidade, referentes ao gerenciamento das Universidades e Institutos. Com média de divulgação de $86,82 \%$, a categoria 5 apresenta $50 \%$ de seus itens com um percentual completo de divulgação, ou seja, 20 de seus itens apresentam $100 \%$ de divulgação em todos os Institutos e Universidades públicas pesquisadas. A variação da dívida (item 5) foi encontrada em todos os portais, porém em instituições como UFCSPA e UFPEL foram localizadas variações referentes ao ano de 2017. Na UFRGS, UFSM e UNIPAMPA a variação da dívida foi encontrada sobre os anos 2018, 2016 e 2009, respectivamente.

Apesar do acesso ao parecer de auditoria ou ao parecer da CGU com dois ou mais anos ter um índice de divulgação alto $(90,91 \%)$ (item 28 ), apenas 3 instituições apresentaram acesso ao parecer de auditoria ou ao parecer da CGU do último ano (item 40), o que ocasionou um índice percentual de 27,27\% sobre este item, portando o menor índice de divulgação sobre toda categoria.

Informações financeiras como fluxos de caixa (item 29), alocação de custos indiretos (item 31), fornecedores (item 32), subsídio para pesquisa (item 33), depreciação (item 34), ativos não correntes (item 35), variação e ativos não correntes (item 36), identificação das políticas contábeis aplicadas 
para a elaboração da informação contábil (item 37) e revisão financeira (item 38) são itens que estão entre $82 \%$ e $54 \%$ de divulgação. Entretanto, estes percentuais deveriam ser maiores porque, segundo Zorzal (2015), estas informações financeiras implicam diretamente no processo de tomada de decisões, sendo sua divulgação essencial para que os stakeholders identifiquem as ações financeiras da instituição de forma ampla e clara.

Com índice de 36,36\%, o acesso aos orçamentos e execução orçamentária do último ano (item 39) é identificado apenas no IFFar, no IFSul, na UFSM e na FURG. Cabe ressaltar que nas demais IES, apesar de não terem sido encontrados os orçamentos e execução orçamentária do último ano, houve algumas instituições que apresentaram este item referente ao ano de 2017: UFCSPA, UNIPAMPA e UFRGS. O item 39 foi encontrado com ano 2016 na UFFS, 2014 na UERGS e houve algumas ressalvas nas instituições IFRS e UFPEL, pois o IFRS apresentava o caminho para este item, porém quando acessado repassava o seguinte aviso: "em construção". Já na UFPEL o caminho foi encontrado, entretanto não apresentou o conteúdo solicitado no item.

Nesta categoria (5) a média geral de divulgação dos IFs alcançou o índice de $86,67 \%$, quase o mesmo percentual alcançado pelas UFs (86,88\%). Também foi possível identificar que os Institutos tiveram uma quantidade maior de itens com $100 \%$ de divulgação, pois dos 40 itens que compõem a categoria, 30 deles são totalmente divulgados nos 3 institutos pesquisados. 0 item menos divulgado por ambos os grupos de instituições é relacionado ao acesso ao parecer de auditoria ou ao parecer da CGU do último ano (item 40), apresentado por apenas 1 IF e 3 UFs.

Chamada de "Características da informação financeira", a categoria 6 estabelece uma relação mais específica sobre os aspectos financeiros que devem estar contidos nas IES. Esta categoria compõe uma estrutura formada por 6 itens ligados às características da informação financeira, que conforme Pessôa (2013), busca verificar se estes aspectos dimensionais interferem na informação financeira que é divulgada pelas instituições.

Esta categoria apresenta média de divulgação de 66,69\%. A média geral de divulgação encontrada nos IFs foi de 55,56\%, uma média menor se comparada à média geral das UFs (70,83\%). 0 único percentual de divulgação que alcançou a sua totalidade nesta categoria foi o item 1: Comparabilidade da informação, que segundo Pessôa (2013), quando divulgada, essa comparabilidade permite que a instituição defronte seus relatórios de gestão, demonstrações contábeis e também suas prestações de contas. O item de menor divulgação é o 6: caráter completo da informação (se existe a possibilidade de consultar a Contabilidade Geral na página web). Essas informações, de acordo com Pessôa (2013), geralmente estão espalhadas entre as diversas páginas do portal da instituição como, por exemplo: reitoria, administração, planejamento, entre outros.

Em relação ao segundo item da categoria: relevância da informação, este foi fortemente divulgado nas instituições, e apenas em duas UFs (UFPEL e UERGS) não foi possível verificar se a informação financeira é divulgada em seção específica, com valores totais agrupados. Porém, somente nos Institutos não foram encontradas informações dos itens 5 e 6, referentes à índices, gráficos, imagens e comentários de apoio para apresentar a informação financeira e a divulgação da contabilidade geral em página web permitindo acessar todos os critérios contábeis, depreciações, demonstrativos contábeis, entre outros (PESSÔA, 2013). Três dos seis itens da categoria apresentam 100\% de divulgação nos IFs, entretanto, dois dos seis itens não são encontrados em nenhum dos Institutos. Apenas um item é $100 \%$ divulgado por todas as UFs. 
A categoria 7 diz respeito à Informação sobre Responsabilidade Social, que retratam aspectos econômicos, sociais e ambientais. Essa categoria reflete questões ligadas à proteção ambiental e à responsabilidade de economia e preservação dos recursos naturais (KON, 2013). A média de divulgação encontrada é de 63,64\%, sendo que nenhum de seus 3 itens apresentaram 100\% de divulgação sobre as IES. O item 3 (com a menor divulgação) é referente a informação sobre indicadores de responsabilidade econômica, do qual, segundo Pessôa (2013), raramente são divulgados pelas instituições e, nas mínimas ocasiões que ocorre, é divulgado de maneira parcial.

A responsabilidade social (item 1 ) apresentou um percentual de divulgação bem superior aos demais presentes na categoria (90,91\%), ou seja, significa que grande parte das instituições utiliza processos de redução de dificuldades e integra estratégias de que atendam aos requisitos de sustentabilidade social e econômica resultando em um desenvolvimento institucional sustentável (KON, 2013).

Sobre os aspectos de responsabilidade social, encontrados no item 1, pode-se afirmar que todas as Universidades divulgam essas informações, assim como as do item 2 (responsabilidade ambiental). Apenas em um IF não foi encontrada informação referente à responsabilidade social, e somente no IFRS foram identificadas informações de responsabilidade ambiental. Em se tratando da divulgação da informação sobre indicadores de responsabilidade econômica (item 3), como critérios de avaliação de fornecedores, política do consumo consciente, entre outros, foram identificadas publicações somente no IFFAR e na UFPEL.

Quanto à categoria 8, referente às condições de qualidade administrativa e acadêmica da instituição, Oliveira, Fonseca e Amaral (2006) ressaltam a relevância da mesma para a comunidade, pois aborda aspectos que não só estão ligados às conquistas acadêmicas, como também em processos de avaliação da instituição gerenciando a qualidade em que o ensino e programas de extensão que estão sendo aplicados no sistema educacional. A média percentual geral de divulgação encontrada nesta categoria é de $78,18 \%$. Os itens que foram $100 \%$ divulgados por todas as IES pesquisadas são aqueles ligados aos informes de autoavaliação e autorregulação no âmbito institucional ou de programas (1 item), a relação de prêmios obtidos pela comunidade acadêmica (item 2) e a relação dos resultados dos exames de qualidade como ENADE, IGC e CPC (item 3). Informações relacionadas à certificação qualidade ISO não foram identificadas em nenhum dos portais das instituições pesquisadas. Dessa forma, as UFs são representadas com um percentual geral médio de $80 \%$ enquanto os IFs dispõem de 73,33\%.

A categoria 9 é composta por 20 itens que, conforme Rosario, Pérez e Cañadas (2011) referem-se aos mecanismos que possibilitam a facilidade de navegação na web, permitindo que todos os indivíduos (mesmo com algum tipo de deficiência) possam acessar e compreender o conteúdo exposto no site. Esta categoria apresenta média de divulgação geral de 76,36\%, sendo que 9 dos 20 itens são divulgados em todas as instituições pesquisadas, ou seja, todas as informações relacionadas à data da última atualização (item 1), seção para informação financeira e orçamentária (item 2), prestação de contas (item 3), motores que facilitam acesso (item 4), downloads de arquivos (item 5), endereços e contatos (item 6), seções específicas para cada tipo de informação (item 7), documentos em diferentes formatos (item 8) e diferenciação de links internos e externos (item 9).

Cabe ressaltar algumas particularidades, por exemplo, no item 2, o qual solicita uma seção específica que agrupe a informação financeira e orçamentária que difunde, pode-se identificar que somente 0 IFSul apresenta estas informações referentes ao ano de 2018 e a UFRGS ao de 2017. Sobre o item 
que corresponde aos formatos eletrônicos utilizados para divulgação de informações financeiras (item 8), pôde-se verificar que 9 das 11 instituições apresentaram informações em PDF e 2 das 11 em formato Excel.

Apesar do item 10 apresentar índice de divulgação de 81,82\%, não foram encontradas informações em outros idiomas na UERGS e na UFCSPA. Já no IFRS, no IFSul e na UFFS foi possível encontrar informações em libras. Na UFPEL, na FURG e na UFRGS há dois idiomas distintos, na UNIPAMPA três e nas instituições como IFFar e UFSM, cinco. Nesta categoria, as médias percentuais gerais dos IFs e UFs também foram bem próximas, 75\% nos IFs e 76,88\% nas UFs. Os IFs apresentaram 11 dos 20 itens com 100\% de divulgação, enquanto as UFs apresentaram apenas 9. Em contrapartida, as UFs não tiveram nenhum item com 0\% de divulgação, enquanto os IFs apresentaram 2.

A categoria 10, correspondente à E-Serviços, apresentou uma média de divulgação de 89,77\%. Nela são analisados itens relacionados a características da página web que facilitam serviços e processos de gerenciamento acadêmico e institucional. Dentre os itens mais divulgados estão aqueles relacionados à facilidade de download de formulários e impressos (item 1), a tramitação sobre o pagamento das transações administrativas (item 2) e o e-learning na educação formal (também conhecido como ensino não presencial) (item 3), que apresentam 100\% de divulgação em todas as IES. Sete, dos oito iten,s são $100 \%$ divulgados pelos IFs, enquanto as UFs apresentam somente três itens com divulgação plena. O item 8, "Facilita-se o download de formulários e impressos para as tramitações administrativas de cursos de aprimoramento" não foi divulgado em nenhum dos IFs, e foi divulgado por dez das onze universidades.

A categoria 11, relacionada a participação eletrônica, aborda questões referentes as ferramentas disponibilizadas pelo portal para estabelecer relações mais interativas e completas entre a comunidade e as IES, além disso é a última categoria analisada.A média percentual geral encontrada nesta categoria é de $87,88 \%$. A média de divulgação geral encontrada nos IFs e UFs nesta categoria é de $92,59 \%$ e $86,11 \%$ respectivamente. Além disso, oito dos nove itens presentes na categoria são $100 \%$ divulgados pelos IFs, enquanto apenas cinco destes são $100 \%$ divulgados pelas UFs. Cinco, dos nove itens presentes na categoria apresentam percentual completo de divulgação, tais como: caixa de reclamações ou sugestões (item 1), foros de discussão na web da Universidade (item 2), pesquisas de opinião (item 3), apresentação dos endereços de contato das pessoas responsáveis pelos serviços prestados na Universidade (item 4) e seção com perguntas e respostas (item 5).

Ao fim da coleta, pôde-se determinar o IndexDUF de cada IES pública do Rio Grande do Sul. Dessa forma, foi possível identificar quais das instituições analisadas demonstra maior transparência sobre os itens compostos pelo IndexDUF nos seus portais eletrônicos. Referente aos IFs, os 3 analisados tiveram um percentual geral de divulgação relativamente próximo, pois o IFSul, o qual conta com menor índice percentual, apresentou média geral sobre todas as categorias de $73,51 \%$ sendo seguido pelo IFRS com média percentual de 75,76\%. Com maior percentual de divulgação destaca-se o IFFar, com média de $78,71 \%$.

Das UFs, a com menor média de divulgação geral entre todas as Universidades está a UERGS, a única Universidade Estadual presente no estudo, que apresentou índice de 69,82\%. A segunda Universidade com menor índice de transparência é a UFCSPA, 78,41\%, uma média bem próxima da UNIPAMPA, de 79,62\%. A Universidade com maior média de divulgação geral encontrada foi a UFFS, com 89,19\%, acompanhada pela UFRGS, com índice de $87,17 \%$, seguida pela FURG com 86,59\% de transparência. 
A UFSM e UFPEL tiveram médias percentuais gerais bem próximas, de $85,43 \%$ e $84,75 \%$ respectivamente.

\section{CONCLUSÃO}

Por meio desta investigação, pode-se comparar o índice IndexDUF de transparência das informações fornecidas pelos Portais Eletrônicos dos Institutos e Universidades Públicas do Rio Grande do Sul. A categoria mais divulgada por todas as IES públicas pesquisadas foi a de Atividades acadêmicas (extensão), a qual alcançou uma média de divulgação de $90,91 \%$ sobre todas as instituições. Para os IFs, a categoria 11, E-participação, alcançou o índice de 92,59\% de divulgação. Já para as UFs, a categoria mais divulgada diz respeito às Atividades acadêmicas (extensão), com 91,67\% de transparência.

Em se tratando somente de UFs, a média de divulgação geral foi de $82,62 \%$, ou seja, encontra-se acima da média geral dos IFs, que representa 75,99\%. As UFs, apesar de apresentarem percentuais maiores que os IFs $(82,62 \%)$, ainda precisam melhorar muito para serem consideradas plenamente transparentes, principalmente as IES como UFCSPA e UNIPAMPA, que se encontram distantes das demais em termos percentuais de transparência pelo IndexDUF.

A instituição que demonstrou maior percentual de divulgação foi a UFFS, com média de 89,19\% de transparência sobre as 11 categorias do IndexDUF. Em contrapartida, a IES que ocupou o posto de menor média de divulgação foi a UERGS, com apenas $69,82 \%$ de transparência. Pôde-se concluir que nenhuma das 11 instituições é $100 \%$ transparente e que a quantidade máxima de itens divulgados foi de 128, pela UFFS. Ainda, cabe ressaltar que todas as IES divulgaram pelo menos 97 dos 139 itens que compõem o IndexDUF.

Entende-se que esta pesquisa contribuiu para ampliar o conhecimento da sociedade sobre os aspectos ligados a transparência de informações nos portais eletrônicos das IES públicas. Ainda, possibilita às instituições avaliadas no estudo a identificação de aspectos que não estão presentes em seus portais, permitindo o aperfeiçoamento destes mecanismos para estabelecer uma inter-relação cada vez maior e mais transparente com a sociedade.

Dentre as limitações encontradas na realização do estudo, destaca-se que a métrica utilizada se trata de um índice binário, sendo apenas identificada a existência ou inexistência do item no portal da instituição, ou seja, o índice não é ponderado e nem graduado, pois não são atribuídos pesos distintos para cada item, tornando-os todos equivalentes. Outro ponto a ser ressaltado é que apesar deste estudo tratar-se de um censo, existe uma população muito maior de IES públicas no país, podendo ser comparadas entre Estados, indicando quais IES e quais Estados apresentam maior índice de transparência, sendo esta uma sugestão para pesquisas futuras.

\section{Notas}

${ }^{1}$ Os itens são numerados para cada categoria. 


\section{REFERÊNCIAS}

AGOSTINETO, Raquel Crestani; RAUPP, Fabiano Maury. Prestação de contas por meio de portais eletrônicos: um estudo em câmaras municipais da grande Florianópolis. Revista Universo Contábil, Blumenau, v. 6, n. 3, p. 64-79, jul./set. 2010.

BRASIL. Lei de Acesso à Informação. Lei ordinária n. ${ }^{0}$ 12.527, de 18 de novembro de 2011. Presidência da República. Casa Civil. Subchefia para Assuntos Jurídicos. Brasília, 2011. Disponível em: <http://www.planalto.gov.br/ccivil_03/_ato2011-2014/2011/lei/l12527.htm>. Acesso em: 01 abr. 2019.

CATÓLICO, Diego Fernando. Revelación y divulgación de información financiera y no financiera das universidades públicas en Colombia. Revista da Facultad de Ciencias Económicas. Nueva Granada, v.20, n.1, p.57-76, jun. 2012.

DAVOK, Delsi Fries. Qualidade em educação. Revista Avaliação da Educação Superior, Campinas, v.12, n.3, p.505-513. 2007.

DIXON, Keith; COY, David; TOWER, Greg. External reporting by New Zealand Universities 1985-1989. Improving accountability. Financial Accountability and Management, New Jersey, v.7, p.159178. 1991. Disponível em: <https://onlinelibrary.wiley.com/doi/abs/10.1111/j.14680408.1991.tb00348.x>. Acesso em: 05 abr. 2019.

FARACO, Bruno Pereira. Transparência das Informações Públicas nos Portais das Instituições Federais de Educação Profissional da Região Sul do Brasil. 2015. $123 \mathrm{f}$. Dissertação (Mestrado em Planejamento e Governança Pública) - Universidade Tecnológica Federal do Paraná, Curitiba, 2015.

FARIA, Maria José da Silva. Tipos de divulgação da informação financeira e não financeira de responsabilidade social empresarial. Cadernos EBAPE.BR, Rio de Janeiro, v. 15, n. 9, p. 534-558, set. 2012.

INDOLFO, Ana Celeste. Políticas de informação, comunicação e inovação em serviços de sistemas de saúde. In: CUNHA FJAP. LÁZARO, CP.; PEREIRA, HBB. Conhecimento, inovação e comunicação em serviços de saúde. Rio de Janeiro: FIOCRUZ, 2014.

KON, Anita. Responsabilidade social das empresas como instrumento para o desenvolvimento: a função da política pública. Planejamento e políticas públicas, [s. I.], v.1, n. 41, p. 45-88, jul./dez. 2013.

LIMA, Aline Ferreira et al. A importância do ensino, pesquisa e extensão da formação profissional. In: JORNADA IBERO-AMERICANA DE PESQUISAS EM POLÍTICAS EDUCACIONAIS E EXPERIÊNCIAS INTERDISCIPLINARES NA EDUCAÇÃO, n. 2. 2017, Natal. Anais eletrônicos... Natal: Even3, 2017. Disponível em: <https://even3storage.blob.core.windows.net/anais/53150.pdf>. Acesso em: 30 abr. 2019.

MALHOTRA, Naresh K. Pesquisa de marketing: uma orientação aplicada. 6. ed. Porto Alegre: Bookman, 2012.

MELO, Douglas Arrais. Transparência da informação pública: uma avaliação de sítios eletrônicos de universidades federais brasileiras. 2019. 128 f. Dissertação (Mestrado em Administração Pública em Rede Nacional) - Universidade Federal de Goiás, Goiânia, 2019. 
MOLINA, Letícia Gorri. Portais corporativos: tecnologia de informação e comunicação aplicadas à gestão da informação e do conhecimento em empresas de Tecnologia de Informação. 2008. 211 . Dissertação (Mestrado em Ciência da Informação) - Universidade Estadual Paulista, Marília, 2008.

MONTEIRO, Alessandra. Aferição do grau de cumprimento às obrigações de transparência ativa constantes da Lei de Acesso à Informação por Universidades Federais do Brasil. 2014. 68f. Dissertação (Mestrado Profissional em Administração Pública) - FGV - Fundação Getúlio Vargas, Rio de Janeiro, 2014.

OLIVEIRA, João Ferreira de; FONSECA, Marília; AMARAL, Nelson Cardoso. Avaliação, desenvolvimento institucional e qualidade do trabalho acadêmico. Revista educar. Curitiba, v. 1, n. 28, p.71-87, 2006.

PESSÔA, Iury da Silva. Determinantes da Transparência das Universidades Federais Brasileiras. 2013. 175 f. Dissertação (Mestrado em Gestão Pública) - Universidade Federal do Espírito Santo, Vitória, 2013.

PESSÔA. Iury da Silva et al. Determinantes da transparência das universidades federais brasileiras: Uma Análise Empírica no ano de 2013. Revista de Gestão e Contabilidade da UFPI, v. 5, n. 2, p. 97-114, 2018.

PLATT NETO, Orion Augusto; CRUZ, Flávio da; VIEIRA, Audí Luiz. Transparência das contas públicas: um enfoque no uso da Internet como instrumento de publicidade na UFSC. Revista Contemporânea de Contabilidade, Florianópolis, v.1, n. 5, p.135-146, 2006. Disponível em: <www.furb.br/universocontabil>. Acesso em: 06 abr. 2019.

RICHARDSON, R. J. Pesquisa social: métodos e técnicas. São Paulo: Atlas, 1999.

RODRIGUES, Georgete Medleg. Indicadores de "transparência ativa" em instituições públicas: análise dos portais de universidades públicas federais. Liinc em Revista, Rio de Janeiro, v.9, n.2, p. 423438, novembro 2013.

ROSARIO, Arturo Haro de; PÉREZ, María del Carmen Caba; CAÑADAS, María del Mar Sánchez. La transparencia de información online: El caso das top 100 universidades del mundo. In: Congresso AECA, 26., 2011, Granada. Anais eletrônicos... Disponível em: <http://www.aeca1.org/pub/on_line/comunicaciones_xvicongresoaeca/cd/31g.pdf>. Acesso em: 06 abr. 2019.

TOMEI Patrícia A. Responsabilidade social de empresas: análise qualitativa da opinião do empresariado nacional. Revista Administração de Empresas, São Paulo, v. 24, n. 4, p. 1-14, out./dez. 1984.

ZÉMOR, Pierre. As formas da comunicação pública. In DUARTE, Jorge (org.). Comunicação Pública. São Paulo: Atlas. 2009.

ZORZAL, Luzia. Transparência das informações das universidades federais: estudo dos relatórios de gestão à luz dos princípios de boa governança na administração pública federal. 2015. 197 p. Tese (Doutorado em Ciência da Informação) - Universidade de Brasília, Programa de pósgraduação em Ciência da Informação, Brasília, 2015. 